\section{A little learning}

Sir - In his evaluation of Steven Rose's book Lifelines: Biology, Freedom,

Determination (Nature 390, 36; 1997), Benno Müller-Hill argues strongly against

Rose's thesis that excessive reductionism is a serious problem in today's biology. He then goes on to say: "In fruitflies, the first stages of development are now well understood and in fish we may know them soon."

This is a ridiculous statement in view of our ignorance of so many basic principles of cells and their interaction. It is presumably the kind of attitude that Rose is critical of: the notion that if you know the genes, you know everything. In my view, it represents an extreme example of reductio ad absurdum.

\section{Gareth Griffiths}

European Molecular Biology Laboratory,

Postfach 102209,

D-69012 Heidelberg, Germany

e-mail:griffith@embl-heidelberg.de

\section{Open access to data}

Sir - The European Database Directive EU 96/9 comes into force in January 1998. It gives copyright protection for electronic and other databases, but brings serious implications for science. Its philosophy confronts the widely accepted principle of 'full and open access to data' at minimum cost, which is vital to sciences such as astronomy, solar-terrestrial and space physics, and geophysical and environmental sciences.

To protect science, I suggest that 'full and open access to scientific data' should become a declared national policy, to which exceptions, for commercial or other reasons, have to be justified.

Many research councils and other agencies do place their scientific data in the public domain, as indeed is required for some categories of data by, for example, the Antarctic Treaty, the European Space Agency convention, and European Commission directive 90/313 on environmental data. The new legislation, however, raises concerns.

First, discussions in US circles suggest that the new all-embracing 'suigeneris' ('database right') may enable 'rights' to data to be hijacked by contractors or other parties involved in the data-handling chain. It therefore behoves research organizations to make sure that their past and future data are secure against any such possibility.

Second, the applied research that often follows from 'academic' research could be seriously hampered unless any required data are in the public domain, as the
European Union allows no 'fair use' exceptions to database copyright for research regarded as 'commercial'.

Furthermore, all 'fair use' (or 'fair dealing') exceptions from copyright, even for the purposes of teaching or research, are at grave risk. Commercial interests are pressing strongly for no 'fair use exceptions' whatever in the United Kingdom.

The Patent Office, which is responsible for the UK legislation to implement EU 96/9, has been inquiring into the economic cost and benefits of such a policy. The terms of this inquiry load the scales against 'fair use', because it is almost impossible to quantify the negative effects of forcing teachers and scientists to buy licences for each and every use of copyright material (apart from a nebulous right to extract 'insubstantial parts' of a database). A strong case is needed to save 'fair use'.

Incidentally, the wide-ranging definition of 'database' includes printed matter, so even the use of a book may fall foul of 'suigeneris'.

\section{Henry Rishbeth}

(Member of ICSU Panel on

World Data Centres)

Department of Physics \& Astronomy,

University of Southampton,

Southampton SO17 1BJ, UK

e-mail:hr@phys.soton.ac.uk 


\section{An early warning of the risks of rocketry}

Sir - The recent study by M. N. Ross et al. on possible stratospheric pollution by rockets (Nature 390, 62-64; 1997) indicates purely local destruction of the ozone layer, with little impact on the overall geographical picture.

Probably the first engineer to alert the international community to the danger of atmospheric pollution by rockets fired into the upper atmosphere was an Englishman, C. F. Dendy Marshall, who, in a letter of 16 February 1932 to the League of Nations, called for international intervention. He was responding to an article in The Times of London of 25 August 1931 that referred to the intention of Dr Darwin O. Lyon to fire a rocket to a height of 50 miles for scientific purposes.

Marshall drew attention to the existence of hydrogen at remote altitudes which without oxygen would not burn, but he warned of the probability of "an explosive belt which the rocket would set on fire in its passage".

He went on to say: "The effect might merely be an unprecedented display of the nature of an aurora.On the other hand, the heat generated might be so great as to bring about the end of the world, so far as we are concerned. There is a risk of wiping everybody out, except those of us who were in the Tube, together with such miners as were at work...."

Marshall quoted Sir James Jeans's estimates that the proportion of hydrogen to oxygen molecules in a given volume of air at ground level was 1:21,000; at a height of 12 miles, 1:875; and at 50 miles about 17:1.

Assuming that the mixture would be flammable between 25 and 30 miles, Marshall calculated that the affected volume would be 47,666 cubic miles, albeit at a very low mean pressure of 0.035 pounds per square inch. The equivalent at ground level pressure would be 113 cubic miles, "enough for a good explosion".

\section{Paul Tunbridge}

30 Avenue Krieg,

1208 Geneva,

Switzerland

\section{Nuclear agency's} research misjudged

Sir - In your News story "Nuclear agency may absorb physics institute" (Nature 389, $895 ; 1997)$, you say "the move is intended to increase CEA's [France's atomic energy commission's] fundamental research capacity, which is widely considered to lag behind the commission's engineering prowess".

Fundamental research is one of the important and recognized goals of CEA, and is carried out in all its divisions, and in particular in the Direction des Sciences de la Matière ('matter', not 'materials'), devoted to basic research in physics and chemistry.

Our institute employs 1,800 CEA staff, and there are 1,200 permanent employees in our laboratories from other agencies or universities, visitors and graduate students. The departments are evaluated every two years by international committees chaired by distinguished scientists.

Together with excellent advice, our laboratories have received much praise from these committees, and many DSM scientists have received national and international awards.

I must also say that I was somewhat surprised by your harsh report, given that our results are often published in Nature.

Catherine Cesarsky

(Director)

Direction des Sciences de la Matière,

CEA/Saclay,

91191 Gif-sur-Yvette Cedex, France

e-mail: catherine.cesarsky@CEA.fr 